\title{
Surgical Management of an Unusual Case of Malignant Middle Cerebral Artery Infarction
}

\author{
Jon Durrani ${ }^{\mathrm{a}, \mathrm{c}}$, Mohammed Rahman ${ }^{\mathrm{b}}$, Phillip Porcellia, Keith Kattner ${ }^{\mathrm{a}}$
}

\begin{abstract}
Decompressive craniectomy for uncontrolled elevated intracranial pressure (ICP) from various etiologies including trauma and strokes is a topic that is gaining attention from many clinicians today. Decompressive craniectomies have been performed for the last century; however, only recently randomized studies have confirmed the beneficial and meaningful neurological outcomes of craniectomies. This case report presents an unusual case of an ischemic stroke of undetermined etiology, that morphed into a malignant middle cerebral artery (MCA) infarction, causing a life-threatening massive cerebral edema requiring a rapid neurosurgical intervention in the form of a decompressive craniectomy.
\end{abstract}

Keywords: Decompressive craniectomy; Malignant middle cerebral artery infarction; Stroke in young people

\section{Introduction}

Stroke in young in people, particularly malignant middle cerebral artery infarctions present many challenges and questions to the treating physician and their team. In the recent literature there have been many studies showing promising outcomes in specific populations if emergent surgical intervention is performed. We present a case of a severe malignant middle cerebral artery infarction in a young person, that was given an opportunity to improve her functional outcome with the use of an emergent and lifesaving surgical intervention.

\footnotetext{
Manuscript accepted for publication January 2, 2013

${ }^{a}$ Neurosurgery Kettering Medical Center/Ohio University, Dayton, OH, USA

${ }^{\mathrm{b}}$ Department of Neurosurgery in Northern Indiana, USA

${ }^{\mathrm{c} C}$ Corresponding author: Jon Durrani, Neurosurgery Kettering Medical

Center/Ohio University, Dayton, OH, USA.

Email: jon.durrani@gmail.com
}

doi: http://dx.doi.org/10.4021/jmc1030w

\section{Case Report}

A 20-year-old female college student who was studying for finals, started feeling tired, weak, and had trouble speaking. Eventually she lost all her strength in the right side of her body and the ability to speak; she was rushed to the emergency room via ambulance. After a thorough clinical evaluation, a non-contrast head CT was performed, and it was determined she was having an ischemic stroke of the left MCA (Fig. 1). After discussion with the family about the risks and benefits of tissue plasminogen activator (tPA) therapy, the family agreed to the therapy and tPA therapy was instituted.

After the tPA therapy was started her condition started to improve, for example, regaining the ability to speak, and recovering some strength on the right side of her body. However, approximately 6 hours after the therapy was initiated, she stated she had again, lost all strength on the right side of her body. When this occurred, another non-contrast CT was performed, and it was found that she was having another ischemic stroke in the same area. At this point tPA therapy could not be instituted due to the fact that she had tPA only 6 hours earlier.

Her condition continued to deteriorate overnight, to a point where she became unconscious and non-responsive. The neurosurgical team was consulted emergently. The neurosurgical evaluation of the patient and the review of a new brain CT indicated that she was developing increased ICP due to massive cerebral edema, which was causing partial brain stem compression (Fig. 2), and she faced a mortality rate of up to $80 \%$ [1]. After thorough evaluation of any and all possible therapeutic options at that time, it was decided that in order to minimize her mortality and maximize the functional preservation, a decompressive craniectomy was the only viable option to lower her ICP. After thorough discussion with the family that outlined the risks and benefits of this procedure, the family agreed to this intervention.

The patient was taken to the operating room emergently. The neurosurgical team completed the procedure approximately within 45 minutes. The left side of her skull was removed and placed in her lower right abdomen for the future use (Fig. 3). She was placed in a pharmacologically 

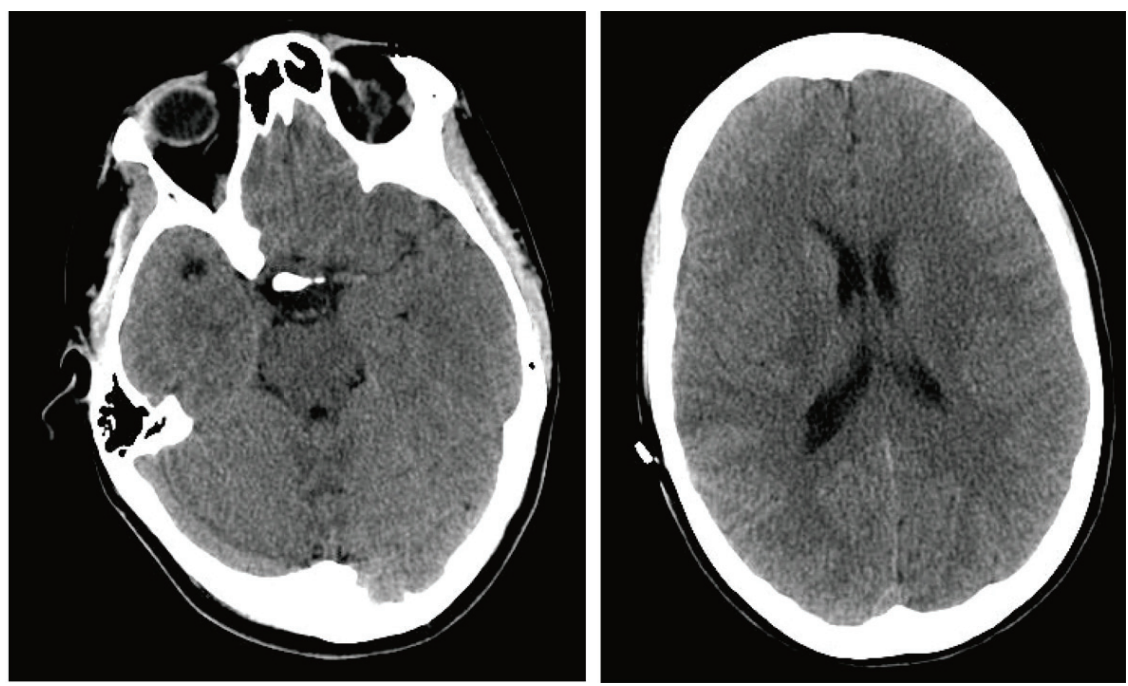

Figure 1. Non-contrast Axial CT Scan in Emergency Room.

induced coma for the next three days, after which time she was weaned off the sedation. Her hospital course was complicated only by a ventilator-associated pneumonia, which was successfully treated with antibiotics.

After three weeks in the intensive care unit, the patient had regained the ability to recognize her surroundings, and attempted to move the right side of her body. After a hospital stay of three and half weeks she was transferred to a rehabilitation facility. At the time of her transfer to the rehabilitation facility her modified Rankin Score (mRS) was 4. At the rehabilitation facility she received further intensive stroke rehabilitation therapy over the next several months and improved to $\mathrm{mRS} 3$, enough to return home.
Soon after the initial admission she had a thorough, however, negative workup for the risk factors and the etiology of this ischemic stroke in such a young person. The only medications that she took regularly were oral contraceptives (name of which could not be determined). She had no family history of hypercoagulability disorders or strokes. The patient did not use alcohol, tobacco, or any street drugs. The precise source of her embolus was never identified.

\section{Discussion}

Thrombolytic therapy has become the mainstay of treatment

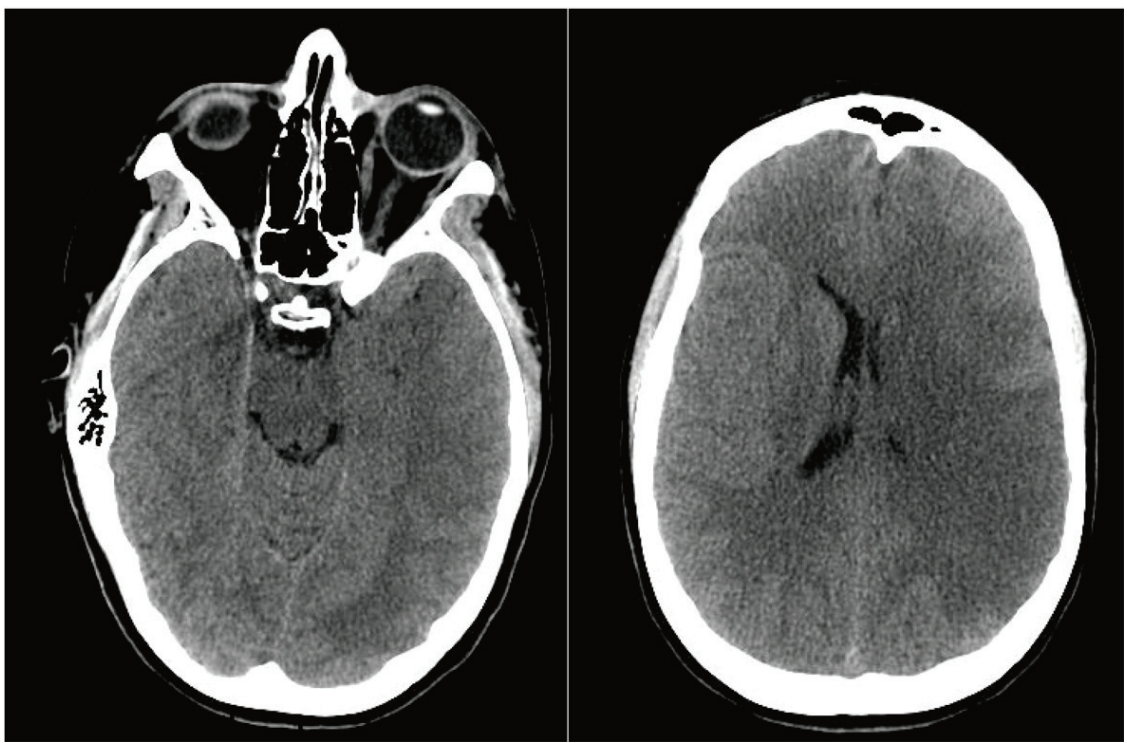

Figure 2. Preoperative Non-contrast Axial CT Scan. 


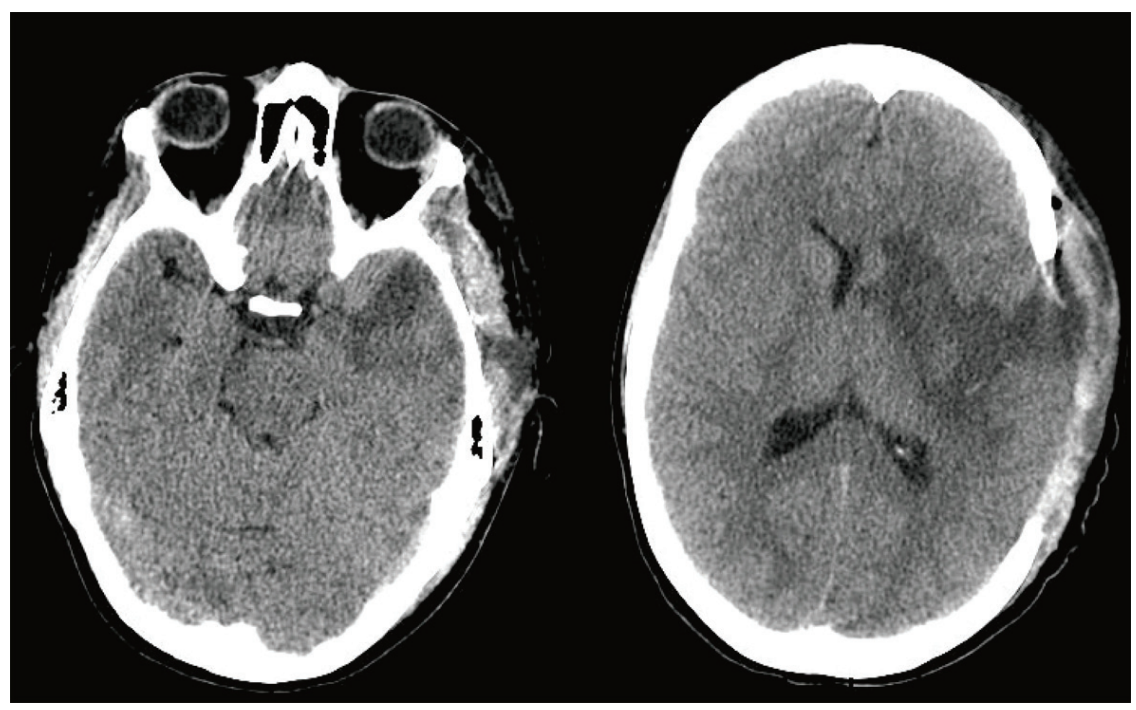

Figure 3. Postoperative Non-contrast Axial CT Scan.

for ischemic strokes in all age groups. Currently tPA is the drug of choice for acute ischemic cerebrovascular accidents (CVA) $[2,3]$. The recurrent stroke rate, both, in control and tPA is $5 \%$ [4]. There is a risk of symptomatic intracerebral hemorrhage (ICH) with the use of tPA as shown in NINDS study: $6.4 \%$ versus $0.6 \%$ [5] with placebo; and ECASS II: $8.8 \%$ versus $3.4 \%$ [3]. Only $3 \%$ of ischemic cerebrovascular accidents occur in patients less than 40 years of age [6].

The treatment of life-threatening, massive cerebral edema after malignant MCA infarction is still a controversial issue in neurology and neurosurgical literature. Such life-threatening cerebral edema usually appears between the

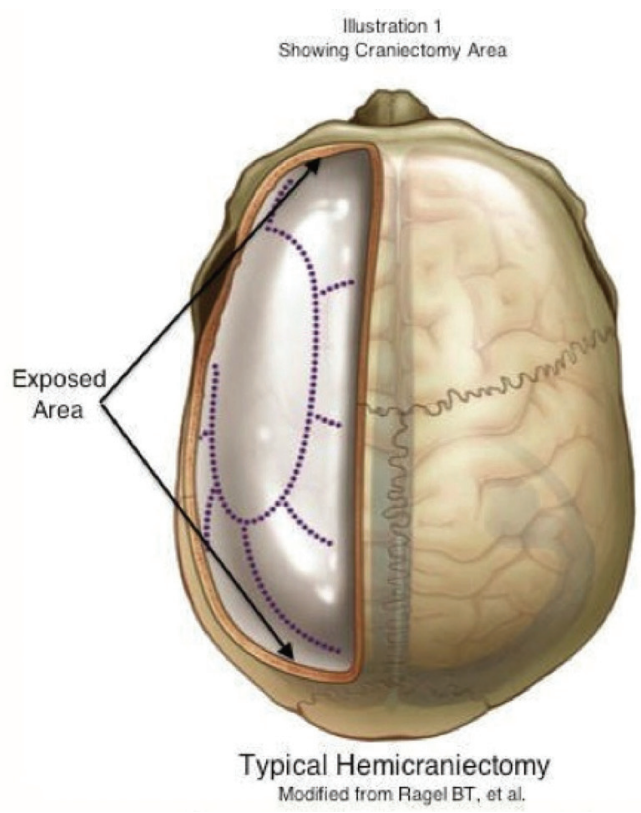

Figure 4. Typical hemicraniectomy/Modified from Ragel BT, et al. second and fifth day after onset of a stroke [7], and they can have a mortality rate of up to $80 \%$ [1]. Several conservative treatments including, mannitol, steroids, barbiturates, hyperventilation, deep sedation and other modalities are available, however the use of such treatments may be ineffective in the case of malignant MCA infarction [8]. Because of the limited benefit of medical treatments, the use of decompressive craniectomy has been recommended for such patients [9].

Kocher in 1901 and Cushing in 1905 separately reported decompressive craniectomies for uncontrollable elevated intracranial pressure $[10,11]$. Decompressive craniectomy is a life-saving neurosurgical procedure performed for refractory elevation of ICP due to trauma, stroke, and a multitude of other etiologies [9]. In the last 10 years there has been extensive studies showing that decompressive craniectomy is a valuable surgical option to improve brain tissue perfusion and oxygenation for middle cerebral artery stroke and traumatic brain injury [12-16].

A well-controlled randomized French study published in 2007 investigated that early decompressive surgery in malignant infarctions of the MCA improved the neurological outcomes in a group of 93 patients [16]. In this study the patients aged 18 years to 60 years were included, and the study concluded that with a decompressive surgery undertaken within 48 hours of stroke onset, morbidity and mortality was reduced and it increased the number of patients with a favorable functional outcome. Decompressive Craniectomy is a fairly extensive surgical operation that involves removal of large portion of the cranium [9] (Fig. 4).

In 2007, the DESTINY trials were performed, and it concluded that it not only decreased mortality but also the analysis of mRS scores showed a statistically significant benefit in functional outcomes [17] (Table 1,2).

A more recent land mark and well-controlled study pub- 
Table 1. Functional Outcome After 12 Months (mRS)

\begin{tabular}{|c|c|c|c|c|c|}
\hline Modified Rankin Score (mRS) & 2 & 3 & 4 & 5 & 6 \\
\hline \multicolumn{6}{|l|}{ Conservative Treatment Group } \\
\hline Number of Patients & 1 & 3 & 1 & 2 & 8 \\
\hline Percentage of Patients in Group & $7 \%$ & $20 \%$ & $7 \%$ & $13 \%$ & $53 \%$ \\
\hline \multicolumn{6}{|l|}{ Surgery Treatment Group } \\
\hline Number of Patients & 4 & 4 & 5 & 1 & 3 \\
\hline Percentage of Patients in Group & $24 \%$ & $24 \%$ & $29 \%$ & $6 \%$ & $18 \%$ \\
\hline
\end{tabular}

Modified from Jutler E, et al [17].

lished in 2010 [9], that was not directly related to strokes, but related to post traumatic recalcitrant intracranial hypertension and the benefits of a decompressive craniectomy in wartime injuries, showed many of the benefits of the early surgical intervention by means of a massive craniectomy. The study was conducted in Iraq and Afghanistan. The wartime study showed that the earlier the craniectomy is performed the better the outcomes due to better control of ICP, therefore eventually leading to increased cerebral perfusion and decreasing or arresting further brain damage. By limiting the amount of damage to the brain either from traumatic brain injury or malignant strokes, gives the patient the potential to have a better neurological recovery and outcome.

The reason decompressive craniectomy works is based on the Munro-Kellie doctrine, which states the cranium is a rigid box. The cranium is filled with blood, CSF, and a "nearly incompressible brain [18]". The total volume of the cranium tends to remain constant and therefore any amount of cerebral edema compromises the brain tissue perfusion and oxygenation and also causes life threatening compression of the brain stem. Thus removing part of the cranium allows a rapid decompression of the contents of the cranium resulting in improvement of brain tissue perfusion and oxygenation as well as reversal of brain stem compression.
In this 20 year-old patient, statistically strokes is very rare, and the fact she suffered 2 consecutive ischemic strokes that morphed into a malignant middle cerebral artery infarction is an even further unusual occurrence. No cause was ever clearly identified for her stroke even after a thorough hematological and cardiovascular workup. The only identifiable risk factor she had was the use of oral contraceptives; which is associated with a nine fold increased risk for a CVA [19].

\section{Conclusion}

Our patient is a 20-year-old female who had an ischemic MCA infarction that initially responded to TPA therapy and then deteriorated and developed into a malignant MCA infarction leading to massive cerebral edema and subsequently partial brain stem compression. Had the neurosurgical team not instituted a quick and definitive intervention, the patient more than likely would not have had a favorable outcome. This case is very unique due to the fact typically catastrophic cerebral vascular accidents do not occur in such young patients without any pre-existing risk factors. The fact that she had not one, but two successive ischemic strokes that ultimately turned into a malignant MCA infarction without

Table 2. Patient Outcomes

\begin{tabular}{lccc}
\hline $\begin{array}{c}\text { Survival After 1 } \\
\text { Year }\end{array}$ & $\begin{array}{c}\text { Surgery Group } \\
\mathbf{n = 1 7}\end{array}$ & $\begin{array}{c}\text { Conservative Treatment Group } \\
\mathbf{n = 1 5}\end{array}$ & $\begin{array}{c}\text { Total } \\
\mathbf{n}=\mathbf{3 2}\end{array}$ \\
\hline Alive & $82 \%$ & $47 \%$ & $66 \%$ \\
Dead & $18 \%$ & $53 \%$ & $34 \%$ \\
\hline
\end{tabular}

Modified from Jutler E, et al [17]. 
any demonstrable risk factors, other than oral contraceptives, makes this case both unfortunate and extremely unique as well. This case is also unique because the idea of using decompressive craniectomy in such a young patient with the given diagnosis was a relatively novel idea and allowed her to have a meaningful neurological recovery.

\section{Disclosures}

There were no financial or conflict of interest disclosures. It was presented at St. Joseph Neuroscience Case Review Conference, Bloomington, IL, May 28, 2010.

\section{Abbreviations}

ICP: intracranial pressure; MCA: middle cerebral artery; tPA: tissue plasminogen activator; mRS: modified Rankin Score; CVA: cerebrovascular accident; ICH: intracerebral hemorrhage

\section{References}

1. Berrouschot J, Sterker M, Bettin S, Koster J, Schneider D. Mortality of space-occupying ('malignant') middle cerebral artery infarction under conservative intensive care. Intensive Care Med. 1998;24(6):620-623.

2. Donnan GA, Davis SM, Chambers BR, Gates PC, Hankey GJ, McNeil JJ, Rosen D, et al. Streptokinase for acute ischemic stroke with relationship to time of administration: Australian Streptokinase (ASK) Trial Study Group. JAMA. 1996;276(12):961-966.

3. Thrombolytic therapy with streptokinase in acute ischemic stroke. The Multicenter Acute Stroke Trial-Europe Study Group. N Engl J Med. 1996;335(3):145150.

4. Hacke W, Kaste M, Fieschi C, von Kummer R, Davalos A, Meier D, Larrue V, et al. Randomised double-blind placebo-controlled trial of thrombolytic therapy with intravenous alteplase in acute ischaemic stroke (ECASS II). Second European-Australasian Acute Stroke Study Investigators. Lancet. 1998;352(9136):1245-1251.

5. Tissue plasminogen activator for acute ischemic stroke. The National Institute of Neurological Disorders and Stroke rt-PA Stroke Study Group. N Engl J Med. 1995;333(24):1581-1587.

6. Hart RG, Miller VT. Cerebral infarction in young adults: a practical approach. Stroke. 1983;14(1):110-114.
7. Hacke W, Schwab S, Horn M, Spranger M, De Georgia M, von Kummer R. 'Malignant' middle cerebral artery territory infarction: clinical course and prognostic signs. Arch Neurol. 1996;53(4):309-315.

8. Hofmeijer J, van der Worp HB, Kappelle LJ. Treatment of space-occupying cerebral infarction. Crit Care Med. 2003;31(2):617-625.

9. Ragel BT, Klimo P, Jr., Martin JE, Teff RJ, Bakken HE, Armonda RA. Wartime decompressive craniectomy: technique and lessons learned. Neurosurg Focus. 2010;28(5):E2.

10. Kocher T. Die Therapie des Hirndruckes, in Holder A (ed): Hirnerschutterung, Hirndruck und chirurgische Eingriffe bei Hirnkrankheiten. Vienna: A Holder, 1901, pp 262-6.

11. Cushing H. The establishment of cerebral hernia as a decompressive measure for inaccessible brain tumors with the description of intermuscular methods of making the bone defect in the temporal and occipital regions. Surg Gynecol Obstet 1905;1:297-314.

12. Chen CC, Cho DY, Tsai SC. Outcome of and prognostic factors for decompressive hemicraniectomy in malignant middle cerebral artery infarction. J Clin Neurosci. 2007;14(4):317-321.

13. Jaeger M, Soehle M, Meixensberger J. Effects of decompressive craniectomy on brain tissue oxygen in patients with intracranial hypertension. J Neurol Neurosurg Psychiatry. 2003;74(4):513-515.

14. Jiang JY, Xu W, Li WP, Xu WH, Zhang J, Bao YH, Ying $\mathrm{YH}$, et al. Efficacy of standard trauma craniectomy for refractory intracranial hypertension with severe traumatic brain injury: a multicenter, prospective, randomized controlled study. J Neurotrauma. 2005;22(6):623-628.

15. Schirmer CM, Ackil AA, Jr., Malek AM. Decompressive Craniectomy. Neurocrit Care. 2008;8(3):456-470.

16. Vahedi K, Hofmeijer J, Juettler E, Vicaut E, George B, Algra A, Amelink GJ, et al. Early decompressive surgery in malignant infarction of the middle cerebral artery: a pooled analysis of three randomised controlled trials. Lancet Neurol. 2007;6(3):215-222.

17. Juttler E, Schwab S, Schmiedek P, Unterberg A, Hennerici M, Woitzik J, Witte S, et al. Decompressive Surgery for the Treatment of Malignant Infarction of the Middle Cerebral Artery (DESTINY): a randomized, controlled trial. Stroke. 2007;38(9):2518-2525.

18. Mokri B. The Monro-Kellie hypothesis: applications in CSF volume depletion. Neurology. 2001;56(12):17461748.

19. Greenburg, M. Handbook of Neuorsurgery. 6th ed. New York,NY: Thieme; 2006:768-774. 